\title{
Venlafaxine extended release $(X R)$ in the treatment of panic disorder
}

\section{Kevin Kjernisted \\ Diane Mclntosh}

University of British Columbia, Vancouver, British Columbia, Canada

\begin{abstract}
Panic disorder is a chronic, recurrent illness, with a lifetime prevalence of about $5 \%$. It is associated with substantial functional impairment, and studies suggest that treatment with medication alone (and no instruction in exposure to feared and avoided situations) is less than optimal. In fact, $40 \%-90 \%$ of patients in long-term follow-up studies in the late $1980 \mathrm{~s}$ and early $1990 \mathrm{~s}$, treated with antidepressants or high potency benzodiazepines alone, remained somewhat symptomatic. Venlafaxine extended release (XR) was effective and well tolerated in both the short-term and long-term treatment of panic disorder. In 12-week trials, venlafaxine XR was significantly more effective than placebo in achieving a panic-free state $(54 \%-70 \%$ vs $34 \%-48 \%, p \leq 0.05)$, and was as effective as paroxetine. In addition, venlafaxine $\mathrm{XR}$ has been shown to produce significantly higher response and remission rates than placebo. Relapse rates were significantly reduced with ongoing venlafaxine XR treatment compared to switching to placebo $(22 \%$ vs $50 \%, \mathrm{p} \leq 0.001)$, in a 6 month study. Importantly, venlafaxine XR significantly improved patient quality of life and functioning, and was generally well tolerated. Keywords: venlafaxine XR, panic disorder, anxiety disorders, quality of life
\end{abstract}

\section{Introduction}

Panic disorder is a prevalent psychiatric disorder, which can significantly impact an individual's emotional and functional wellbeing (Sherbourne et al 1996; Roy-Byrne et al 2000; Ramage-Morin 2004; Kessler, Berglund, et al 2005; Kessler, Chiu, et al 2005). Treatment for panic disorder most often involves antidepressants, however, only about half of patients will become panic free on antidepressants alone (Otto et al 2001; Bakker et al 2002). In addition, follow-up studies of patients with panic disorder at 1 to 5 years after initiation of antidepressants or high potency benzodiazepines demonstrate that $40 \%-90 \%$ of patients remain at least somewhat symptomatic (Noyes et al 1989; Nagy et al 1989, 1993). Clearly, there remains room for improvement in the treatment of panic disorder.

Cognitive behavioural therapy (CBT) is the other mainstay in the treatment of panic disorder. Some form of exposure (individual or group CBT or self-help books) is essential to furthering the treatment response beyond cessation of panic attacks. Exposure helps to eliminate the anticipatory anxiety and agoraphobic avoidance, which are the most functionally disabling aspects of panic disorder with agoraphobia.

Efficacy, safety, and tolerability of venlafaxine extended release (XR) has been established for depression (Smith et al 2002), generalized anxiety disorder (Gelenberg et al 2000), and social anxiety disorder (Allgulander et al 2004). Recently, venlafaxine XR has been approved for use in the treatment of panic disorder in a number of countries. This paper will review the current evidence for clinical efficacy, safety, tolerability, and quality of life improvements with venlafaxine XR in the short and long-term treatment of panic disorder.

\section{Diagnosis of panic disorder}

The diagnostic and statistical manual of mental disorders, text revised (DSM-IVTR), criteria for the diagnosis of panic disorder are shown in Table 1 (APA 2000). 
Panic disorder may be associated with agoraphobia, defined as anxiety about being in places or situations from which escape might be difficult or embarrassing, or in which help may not be available in the event of having an unexpected or situationally-predisposed panic attack or panic-like symptoms (APA 2000).

\section{Burden of panic disorder Prevalence}

Panic disorder is a chronic, recurrent illness associated with substantial functional impairment and cost to the individual and society. Panic attacks have an estimated lifetime prevalence of $15 \%$ (Eaton et al 1994).However, the diagnosis of panic disorder is less common, with a lifetime prevalence of $4.7 \%$ (Kessler, Berglund, et al 2005; Kessler, Chiu, et al 2005). Therefore, many individuals with a history of panic attacks do not have panic disorder. Approximately $30 \%$ of the population will suffer at least one panic attack in any one year, without having any formal psychiatric disorder (Norton et al 1985).

Panic attacks are often seen in mood and anxiety disorders, but also in patients with schizophrenia and borderline personality disorder. Thirty percent of patients with unipolar depression and $60 \%$ of patients with bipolar depression,including mixed states, will have panic attacks as part of their mood disorder (Angst 1996). Prepubertal onset of panic attacks and treatment refractory panic attacks should increase suspicion of bipolar disorder. (Mackinnon et al 2002).

Approximately one-third to one-half of patients with panic disorder have symptoms of agoraphobia (Eaton et al 1994). Panic disorder and agoraphobia are more common in women than men (Eaton et al 1994; Weissman et al 1997). The onset of panic disorder usually occurs in late adolescence or early adulthood (Kessler, Berglund, et al
2005; Ramage-Morin 2004). For patients who present with anxiety symptoms, including panic attacks, for the very first time after the age of 45 , the most likely primary diagnosis is depression.

\section{Impact}

Panic disorder can have a profound impact on an individual's quality of life. Individuals with panic disorder are less likely to work and more likely to be permanently unable to work, compared with those who have never had the disorder (Sherbourne et al 1996; Roy-Byrne et al 2000; RamageMorin 2004). Patients with panic disorder have greater impairment in functioning than patients with diabetes, heart disease, or arthritis (Sherbourne et al 1996).

Approximately $80 \%$ of panic disorder patients experience other co-morbid psychiatric conditions. (Kessler, Berglund, et al 2005). Comorbid depression is particularly common and has a negative impact on outcomes including an increased risk of suicide (Fawcett 1997; Coryell et al 1988; Weissman et al 1999; Roy-Byrne et al 2000; Goodwin et al 2001).

Comorbid medical conditions should also be considered in patients with panic disorder, including respiratory diseases such as asthma (Goodwin et al 2003; Zandbergen et al 1991), vestibular dysfunction (Staab et al 2002), and thyroid disease (hypothyroidism and hyperthyroidism) (Simon et al 2002). Chest pain and palpitations are frequent symptoms of panic attacks and may be difficult to differentiate from cardiac disease. While $43 \%$ of patients presenting to the emergency department with atypical chest pain have been found to have panic attacks or panic disorder (Wulsin et al 1988), the presence of panic disorder does not preclude coronary artery disease (CAD). Anxiety has been shown to increase the risk of CAD and cardiac death (Kawachi, Colditz, et al 1994; Kawachi, Sparrow, et al 1994; Albert et al 2005). The cause

Table I DSM-IV-TR diagnosis of panic disorder (with or without agoraphobia). Reprinted with permission from the Diagnostic and Statistical Manual of Mental Disorders, Fourth Edition, Text Revision. Copyright @ 2000. American Psychiatric Association.

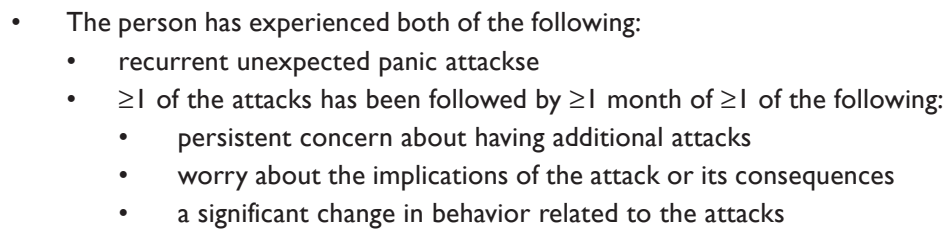

- The presence (or absence) of agoraphobia

- The panic attacks are not due to substance abuse, a medication, or a general medical condition

- The panic attacks are not better accounted for by another mental disorder 
of this increased risk is likely multifactorial. Possibilities include decreased heart rate variability (Tucker et al 1997; Yeragani et al 2000; Sullivan et al 2004) and increased proinflammatory cytokines and cortisol, which are associated with stress diathesis disorders. Additionally, smoking, another risk factor for CAD, is common among panic disorder patients.

\section{Overview of pharmacological treatment of panic disorder}

Pharmacologic treatment, often in combination with cognitive-behavioral therapies, can be tailored for the individual patient based on specific anxiety symptoms, comorbid disorders, and history of side effects (Roy-Byrne et al 1993).

Pharmacotherapeutic interventions that have demonstrated efficacy in treating panic disorder include selective serotonin reuptake inhibitors (SSRIs), the serotonin and norepinephrine reuptake inhibitor (SNRI) venlafaxine $\mathrm{XR}$, tricyclic antidepressants (TCAs), and benzodiazepines. Current published guidelines from Canada, the United Kingdom, Singapore, and Australia and New Zealand generally recommend antidepressants as first line therapy for the treatment of panic disorder (Bandelow et al 2002; Ministry of Health 2003; Royal Australian and New Zealand College of Psychiatrists 2003; Mcintosh et al 2004; Canadian Journal of Psychiatry Clinical Practice Guidelines 2006). SSRIs and TCAs have demonstrated equivalent efficacy, but most guidelines suggest that TCAs are less well tolerated. Generally, antidepressants are preferred over benzodiazepines as first line treatment because, unlike benzodiazepines, antidepressants treat comorbid depression without risk of dependency and the potential for side effects such as excessive sedation, cognitive impairment, and ataxia.

Individuals with panic disorder may have increased sensitivity to medication side effects such as tachycardia, dizziness, dry mouth, and tremor. These side effects are sometimes incorrectly attributed to medical disorders (RoyByrne et al 1993). Anxiety about physical symptoms may increase at the onset of antidepressant treatment; therefore, it is important to start with low doses and educate patients about possible adverse events to reduce distress and prevent nonadherence with treatment.

\section{Defining remission in panic disorder}

The concept of remission and the impact of failing to acheive remission is not as well established in anxiety disorders as in depression (Frank et al 1991; Paykel 1998). However, it is likely that achieving remission in anxiety disorders has a similar positive relationship to outcome as is seen in depression (Ballenger 2001). A number of assessment tools have been designed to quantify the severity of panic symptoms, response to therapy, and functional impairment (Table 2) (Liebowitz et al 2004).

The goals of therapy are to decrease the frequency and severity of panic attacks, as well as to reduce anticipatory

Table 2 Description of Panic Disorder Assessment Scales Reprinted with permission from Liebowitz M, Asnis G, Tzanis E, et al. 2004. Venlafaxine extended release versus placebo in the short-term treatment of panic disorders. New Research Abstracts from the APA Annual Meeting. Copyright (C) 2004. American Psychiatric Association.

Scale Description

Panic and Anticipatory

Anxiety Scale (PAAS)

Panic Disorder Severity Scale (PDSS)

Phobia Scale

Sheehan Disability Scale

Quality of Life Enjoyment and Satisfaction

Questionnaire
Measures the frequency, average duration, average intensity, and type of attack (full- or limited-symptom and expected or unexpected), percentage of time awake spent having anticipatory anxiety and the intensity of the anticipatory anxiety.

A 7-item clinical interview assessment instrument designed to measure the severity of panic disorder symptoms. It rates core features of panic disorder, including frequency of full symptom and limited-symptom panic attacks, distress caused by panic attacks, anticipatory anxiety, agoraphobic fear/avoidance, panic related sensation fear/ avoidance, and work and social impairment.

Evaluates the extent of fear and the avoidance of things or situations that patients fear (if any).

Includes 3 specific domains that capture key aspects of patient disability (work, social life/ leisure, family life/home responsibilities). Responses on these 3 domains are scored on an II-point (0 to I0) discrete analog scale with higher scores representing greater impairment $(0=$ not at all impaired; $10=$ very severely impaired). Also includes a 5 point work and social disability scale ( $I=$ normal activity; $5=$ symptoms prevent normal work or social activities).

Includes domains that measure physical health/activities, subjective feelings of well-being, work, household duties, school/ coursework, leisure time, social relations, general well-being, satisfaction with medication, and overall life satisfaction. Responses are measured on a 5-point Likert scale with higher scores indicating better functioning. 
Table 3 Remission of panic disorder. Adapted with permission from Ballenger J. 200 I. Treatment of anxiety disorders to remission. J Clin Psychiatry, 62(Suppl 12):5-9. Copyright @ 200I. Physicians Postgraduate Press.

\begin{tabular}{ll}
\hline Option I & Option $\mathbf{2}$ \\
\hline - Essentially free of panic attacks & PDSS total score $\leq 3$, with no individual item score $>$ I \\
- No or mild agoraphobic avoidance & \\
- No or minimal anxiety & \\
$\quad$ HAM-A score $\leq 7-10$ & \\
- No functional impairment & \\
$\quad$ Sheehan Disability Scale score $\leq I$ (mildly disabled) & \\
- HAM-D score $\leq 7$ & HAM-D score $\leq 7$ \\
\hline
\end{tabular}

Abbreviations: HAM-A, Hamilton Rating Scale for Anxiety; HAM-D, Hamilton Rating Scale for Depression; PDSS, Panic Disorder Severity Scale.

anxiety, fear-driven avoidance, and impairment in functioning associated with panic disorder (Table 3) (Ballenger 2001; Royal Australian and New Zealand College of Psychiatrists 2003). Suggested criteria for remission of panic disorder are outlined in Table 3 (Ballenger 2001). Patients were considered to have remitted in the placebocontrolled trials outlined in this paper when their Clinical Global Impression - Improvement (CGI-I) $=1$ and they were panic free.

\section{Clinical efficacy of venlafaxine $\mathbf{X} \mathbf{R}$ for panic disorder}

Venlafaxine XR, a structurally novel phenylethylamine antidepressant, has a dual mechanism of action, acting as both a serotonin and norepinephrine reuptake inhibitor (SNRI), with little or no affinity for muscarinic, histaminergic or adrenergic receptors (Muth et al 1986). Potentiation of neurotransmission involves a tonic increase in serotonin and norepinephrine in synaptic clefts throughout the central nervous system. Through norepinephrine reuptake inhibition, which increases exponentially at doses above $150 \mathrm{mg}$, venlafaxine attenuates phasic noradrenergic reactivity (Morilak and Frazer 2004; Blier and Szabo 2005. This is the noradrenergic neuronal firing in response to stressful or threatening stimuli (Cecchi et al 2002; Pardon et al 2002). When there is an increase in extracellular norepinephrine, one would expect a desensitization of alpha2 autoreceptors on the cell body. This does not occur however. If they were desensitized, neuronal firing would increase.This attenuation of noradrenergic neuronal firing could contribute to the anxiolytic effect of venlafaxine.

An early, small, proof-of-concept study in 25 patients, indicating that venlafaxine might be efficacious in panic disorder (Pollack et al 1996), formed the basis of further investigations. Four large, randomized controlled trials are available, demonstrating the robust efficacy of venlafaxine for the short-term (Liebowitz et al 2004; Pollack et al 2004, 2005; Bradwejn et al 2005) and long-term (Ferguson et al 2005) treatment of panic disorder (Table 4). There are also data indicating that venlafaxine offers improved quality of life for patients with panic disorder (Khandker et al 2005).

\section{Placebo-controlled trials}

A multicenter, randomized, placebo-controlled trial evaluated the safety and efficacy of venlafaxine XR in 328 adults with panic disorder, with or without agoraphobia, of at least 6 months duration (Bradwejn et al 2005). Patients were randomized to either flexible-dose venlafaxine XR ( $75 \mathrm{mg} /$ day to $225 \mathrm{mg} /$ day; mean daily dose $115-163 \mathrm{mg}$ ) or placebo for 10 weeks. Treatment with venlafaxine resulted in statistically significant improvement compared with placebo in terms of the percentage of patients free from fullsymptom panic attacks (the primary outcome measure), at weeks 4 and 8 , but not at the final evaluation, $(55.0 \%$ vs $52.4 \%$, respectively; $p=$ nonsignificant) (Table 4 ) (Bradwejn et al 2005).

However, response (defined as CGI-I $\leq 2$; Figure 1) and remission rates (defined as CGI-I $=1$ and panic-free; Figure 2) were significantly higher with venlafaxine $X R$ at endpoint. Other secondary outcome measures, including improvements in the fear and avoidance factors of the Phobia Scale, and in quality of life, were also significantly greater with venlafaxine XR (Bradwejn et al 2005).

Another 10-week, multicenter, placebo-controlled trial randomized 310 patients to either flexible dose venlafaxine XR $(75 \mathrm{mg}$ /day to $225 \mathrm{mg}$ /day; mean daily dose 125.6 $194.1 \mathrm{mg}$ ) or placebo (Liebowitz et al 2004). The only significant difference in baseline characteristics between the groups was a higher percentage of women in the venlafaxine XR group ( $72 \%$ vs $59 \%$ in the placebo group, $\mathrm{p}=0.031$ ). 
Venlafaxine XR-treated patients showed improvement in panic frequency as compared to placebo, but this difference did not achieve statistical significance (panic free: $51.0 \%$ vs $40.6 \%$; $=0.056$ ). However, response rates (CGII score 1 or 2), were significantly higher with venlafaxine XR (71.1\%) compared with placebo $(58.8 \%, \mathrm{p}=0.031)$, and there was a trend toward higher remission rates (CGI-I $=1$ and panic-free) with venlafaxine XR (37.5\% and $27 . \%$, $\mathrm{p}=0.067$ ) (Table 4). Venlafaxine XR-treated patients demonstrated a significant difference from placebo on the Panic Disorder Severity Scale (PDSS) $(\mathrm{p}=0.02)$, and the Phobia Scale measures of fear $(\mathrm{p}=0.007)$ and avoidance $(\mathrm{p}=0.026)$, as well as significant improvements in quality of life measures (Liebowitz et al 2004).

\section{Comparative trials}

Two multicenter, double blind, 12-week trials, including over 1200 patients, have assessed the safety and efficacy of venlafaxine XR compared with paroxetine and placebo for the treatment of panic disorder (Pollack et al 2004, 2005).
The first trial included 634 patients with panic disorder,with or without agoraphobia, randomized to one of four groups: venlafaxine XR $75 \mathrm{mg} /$ day, venlafaxine XR $150 \mathrm{mg}$ /day, paroxetine $40 \mathrm{mg} /$ day or placebo (Pollack et al 2004). There were no significant differences in baseline characteristics between the groups.

Venlafaxine XR $75 \mathrm{mg}$ or $150 \mathrm{mg}$, and paroxetine $40 \mathrm{mg}$ were associated with significant improvements compared with placebo, and there were no significant differences between venlafaxine and paroxetine treatment. The percentages of patients free of panic attacks were: $54 \%$ with venlafaxine XR $75 \mathrm{mg}, 61 \%$ with venlafaxine XR $150 \mathrm{mg}$, $60 \%$ with paroxetine, and $34 \%$ with placebo ( $<<0.001$ for all active treatments vs placebo) (Table 4). Remission was achieved by a significant proportion of venlafaxine XRtreated patients as early as week 4 (venlafaxine $75 \mathrm{mg}$ vs placebo, $\mathrm{p}<0.01$; venlafaxine $150 \mathrm{mg}$ vs placebo, $\mathrm{p}<0.05$ ), and by paroxetine-treated patients as early as week $6(\mathrm{p}<0.05$ vs placebo). In general, the incidence and severity of treatment-emergent adverse events were similar among the three active treatment groups.

Table 4 Double-blind trials evaluating venlafaxine $X R$ in patients with panic disorder.

\begin{tabular}{|c|c|c|c|c|}
\hline $\begin{array}{l}\text { Study } \\
\text { (n value) } \\
\text { Study duration }\end{array}$ & $\begin{array}{l}\text { Treatment } \\
\text { mg/day }\end{array}$ & $\begin{array}{l}\text { Response Rate } \\
\text { CGI-I I or } 2 \\
\%\end{array}$ & $\begin{array}{l}\text { Remission Rate } \\
\text { Panic-free and } \\
\text { CGI-I=I } \\
\%\end{array}$ & $\begin{array}{l}\text { Panic-free } \\
\text { Free of full symptom } \\
\text { panic attacks } \\
\%\end{array}$ \\
\hline $\begin{array}{l}\text { Bradwejn } 2005 \\
(n=328)\end{array}$ & $\begin{array}{l}\text { VEN } 75-225 \mathrm{mg} \\
\text { (flexible dose) }\end{array}$ & 68.1 & 35.6 & 55 \\
\hline $\begin{array}{l}10 \text { weeks } \\
\text { (Bradwejn et al 2005) }\end{array}$ & Placebo & $\begin{array}{l}55.4 \\
p=0.023\end{array}$ & $\begin{array}{l}24.4 \\
p=0.03\end{array}$ & $\begin{array}{l}52.4 \\
p=0.622\end{array}$ \\
\hline $\begin{array}{l}\text { Liebowitz } 2004 \\
(n=3 \mid 0)\end{array}$ & $\begin{array}{l}\text { VEN 75-225 mg } \\
\text { (flexible dose) }\end{array}$ & 71.1 & 37.5 & 51 \\
\hline $\begin{array}{l}10 \text { weeks } \\
\text { (Liebowitz et al 2004) }\end{array}$ & Placebo & $\begin{array}{l}58.8 \\
P=0.031\end{array}$ & $\begin{array}{l}27.5 \\
p=0.067\end{array}$ & $\begin{array}{l}40.6 \\
p=0.056\end{array}$ \\
\hline $\begin{array}{l}\text { Pollack } 2004 \\
(n=634) \\
12 \text { weeks }\end{array}$ & $\begin{array}{l}\text { VEN } 75 \mathrm{mg} \\
\text { VEN } 150 \mathrm{mg} \\
\text { PRX } 40 \mathrm{mg}\end{array}$ & $\begin{array}{l}77 \\
79 \\
81\end{array}$ & $\begin{array}{l}45^{*} \\
47^{* *} \\
46^{* *}\end{array}$ & $\begin{array}{l}54 \\
61 \\
60\end{array}$ \\
\hline (Pollack et al 2004) & Placebo & $\begin{array}{l}56 \\
p<0.00 \text { I (vs placebo) }\end{array}$ & $\begin{array}{l}27 \\
{ }^{*} \mathrm{p}=0.00 \mathrm{I} \\
{ }^{*} \mathrm{p}<0.00 \mathrm{I} \text { (vs placebo) }\end{array}$ & $\begin{array}{l}34 \\
\mathrm{p}<0.00 \mathrm{I} \text { (vs placebo) }\end{array}$ \\
\hline $\begin{array}{l}\text { Pollack } 2005 \\
(\mathrm{n}=624)\end{array}$ & & & $\begin{array}{l}\text { Panic-free and CGI-S I } \\
\text { or } 2\end{array}$ & \\
\hline 12 weeks & VEN $75 \mathrm{mg}$ & 83.2 & $42^{*}$ & $64.7^{*}$ \\
\hline (Pollack et al 2005) & $\begin{array}{l}\text { VEN } 225 \mathrm{mg} \\
\text { PRX } 40 \mathrm{mg}\end{array}$ & $\begin{array}{l}88.6 \\
83.8\end{array}$ & $\begin{array}{l}51 * * \\
39 * * *\end{array}$ & $\begin{array}{l}70.0 * \dagger \\
58.3 * *\end{array}$ \\
\hline & Placebo & $\begin{array}{l}62.3 \\
\mathrm{p}<0.00 \mathrm{I} \\
\text { (vs placebo) }\end{array}$ & $\begin{array}{l}27 \\
* \mathrm{p} \leq 0.01 \\
* * \mathrm{p}<0.001 \\
* * * \mathrm{p}<0.05 \text { (vs placebo) }\end{array}$ & $\begin{array}{l}47.8 \\
*_{p}<0.001 \\
* * p<0.05 \text { (vs placebo) } \\
t_{p}<0.05 \text { (vs paroxetine) }\end{array}$ \\
\hline
\end{tabular}

Abbreviations: CGI-I, Clinical Global Impressions - Improvement; CGI-S, Clinical Global Impressions - Severity; VEN, venlafaxine XR; PRX, paroxetine; XR, extended release. 




Figure I Response rates with venlafaxine XR and placebo over time. Copyright (C) 2005. Reprinted with permission from Bradwejn J, Ahokas A, Stein DJ, et al. 2005. Venlafaxine extended-release capsules in panic disorder: Flexible-dose, double-blind, placebo-controlled study. Br J Psychiatry, 187:352-9.

Notes: ${ }^{*} \mathrm{p}<0.05$ vs placebo; ${ }^{*} \mathrm{p}<0.0 \mathrm{I}$ vs placebo; Response defined as $\mathrm{CGI}-\mathrm{I}=\mathrm{I}$ or 2.

Abbreviations: CGI-I, Clinical Global Impressions - Improvement; XR, extended release.

The second comparative trial was similar in design and included 624 adults with panic disorder,with or without agoraphobia, who were randomized to venlafaxine XR $75 \mathrm{mg}$ /day, venlafaxine XR $225 \mathrm{mg} /$ day, paroxetine $40 \mathrm{mg} /$ day or placebo (Pollack et al 2005). There were no significant differences in baseline and demographic characteristics between the groups.

Treatment with venlafaxine XR $75 \mathrm{mg}$, venlafaxine XR $225 \mathrm{mg}$, and paroxetine $40 \mathrm{mg}$ was associated with significant improvements compared with placebo. The percentage of patients free of panic attacks was $64.7 \%$ with venlafaxine XR $75 \mathrm{mg}, 70.0 \%$ with venlafaxine XR $225 \mathrm{mg}$, $58.3 \%$ with paroxetine, and $47.8 \%$ with placebo $(\mathrm{p}<0.001$ for both venlafaxine groups vs placebo, $\mathrm{p}<0.05$ for paroxetine vs placebo) (Table 4) (Pollack et al 2005). The venlafaxine XR $225 \mathrm{mg}$ group had a statistically significant higher percentage of panic-free patients $(p<0.05)$ and significantly greater PDSS score improvement $(\mathrm{p}<0.05)$ at endpoint than paroxetine. Sustained remission (panic-free and CGI-Sustained [CGI-S] of 1 or 2) was achieved in a significant proportion of venlafaxine XR-treated patients by week 6 , and in paroxetine-treated patients by week 8 . Response and remission rates were comparable between the active treatment groups, with over $75 \%$ of patients considered responders, and $39-51 \%$ of patients considered remitters. All 3 active treatment groups showed greater improvement than the placebo group on the Hamilton Rating Scale for Anxiety (HAM-A) and the Hamilton Rating Scale for Depression (HAM-D). The authors concluded that venlafaxine XR and paroxetine were safe, efficacious, and well tolerated in the short-term treatment of panic disorder.

\section{Data in adolescents and children}

A 10-week, double blind, placebo controlled trial examined the safety and efficacy of flexible-dose venlafaxine XR in 48 adolescents (aged 12 to 17 years) with panic disorder,with or without agoraphobia (Albano et al 2006). There were no significant differences between the venlafaxine XR and placebo groups at any time point for panic attack frequency, PDSS total score, or response rates (defined as CGI-I $=1$ or 2) (Albano et al 2006).Furthermore, there was no evidence of an increased risk of adverse events in this patient group. There were no deaths in the study, no indicators of suicidality, no serious adverse events, and no discontinuations due to adverse events in the venlafaxine group. However, physicians should follow patients closely and be on alert for signs of suicidal ideation in patients taking venlafaxine XR or any other antidepressant. Starting with low doses may minimize the risk of increasing anxiety and panic attacks, which are independent risk factors for increased suicide attempts in depressed adults (Fawcett 1997).

\section{Long-term efficacy and relapse prevention}

The long-term efficacy and safety of venlafaxine XR has been examined in a multicenter, randomized, placebocontrolled trial (Ferguson et al 2005). Patients who were responders ( $\leq 1$ full symptom panic attack per week in the last 2 weeks of open-label treatment and a CGI-I $\leq 2$ ) to venlafaxine XR (flexible dose 75-225 mg per day; mean daily dose $172.1 \mathrm{mg}[ \pm 53.2 \mathrm{mg}])$ in a 12 -week, open label 
study, were randomized to continue receiving their openlabel dosage of venlafaxine XR (mean daily dose $164.9 \mathrm{mg}$ per day during the initial 2 week period of the double-blind phase) or switch to placebo for up to 6 months (venlafaxine $\mathrm{XR}=89$, placebo $\mathrm{n}=80$ ). Relapse was defined as having 2 or more full-symptom panic attacks per week for 2 consecutive weeks or discontinuing therapy because of loss of effectiveness. Venlafaxine XR was significantly better than placebo in preventing relapse in patients who had responded to open-label treatment. According to the Kaplan-Meier survival analysis, $22.5 \%$ of patients in the venlafaxine XR group relapsed, compared with $50 \%$ of patients in the placebo group $(\mathrm{p}<0.001)$ (Ferguson et al 2005).

Venlafaxine XR demonstrated significant improvement in most other secondary efficacy variables, including the percentage of patients who were panic-free on venlafaxine XR (52.8\%) compared to placebo $(31.3 \%)(p=0.005)$, and mean panic frequency $(\mathrm{p}<0.001)$. There were also significant improvements in the PDSS, anticipatory, psychic, and somatic anxiety, and fear and avoidance, as well as CGI-S and quality of life in the venlafaxine XR group compared with placebo (Ferguson et al 2005). Venlafaxine XR-treated patients were significantly less likely to withdraw from the study for any reason, than were patients treated with placebo $(\mathrm{p}<0.001)$.

\section{Improved quality of life}

Panic disorder is characterized by substantial impairment in patient-reported quality of life attributable to both emotional and physical health (Katerndahl and Realini 1997). The National Institutes of Health Consensus
Development Conference on the Treatment of Panic Disorder has recommended that measures of patientreported quality of life and functioning are essential and should be included in clinical studies in panic disorder (Shear and Maser 1994).

In placebo-controlled short term trials, venlafaxine XR improved 3 out of 4 Sheehan Disability Scale (SDS) domains, and most of the domains assessed with the Quality of Life Enjoyment and Satisfaction Questionnaire (Q-LESQ) (Liebowitz et al 2004; Bradwejn et al 2005). In the longterm trial, venlafaxine XR was significantly better than placebo in improving SDS work, social life and leisure activities, family life and home responsibilities, and global work and social disability scores over 6 months of treatment $(p<0.001)$ (Ferguson et al 2005). Venlafaxine XR-treated patients also showed significantly greater improvement from baseline on all but 1 of the 10 Q-LES-Q subscales (school/ course work) compared with placebo at 6 months (Ferguson et al 2005).

The two 12-week, multicenter studies comparing venlafaxine with paroxetine and placebo included secondary analyses of functional impairment (SDS) and quality of life (Q-LES-Q) (Zhang et al 2004; Khandker et al 2005). At baseline, patients were most impaired on the Q-LES-Q subscales relating to school/course work, overall life satisfaction, satisfaction with medication, and physical health and activities (Zhang et al 2004; Khandker et al 2005). At study end, venlafaxine XR was associated with improvements in 7 to 9 of the 10 subscales of the Q-LESQ, and paroxetine with improvements in 7 to 10 of the 10 subscales (Zhang et al 2004; Khandker et al 2005). In

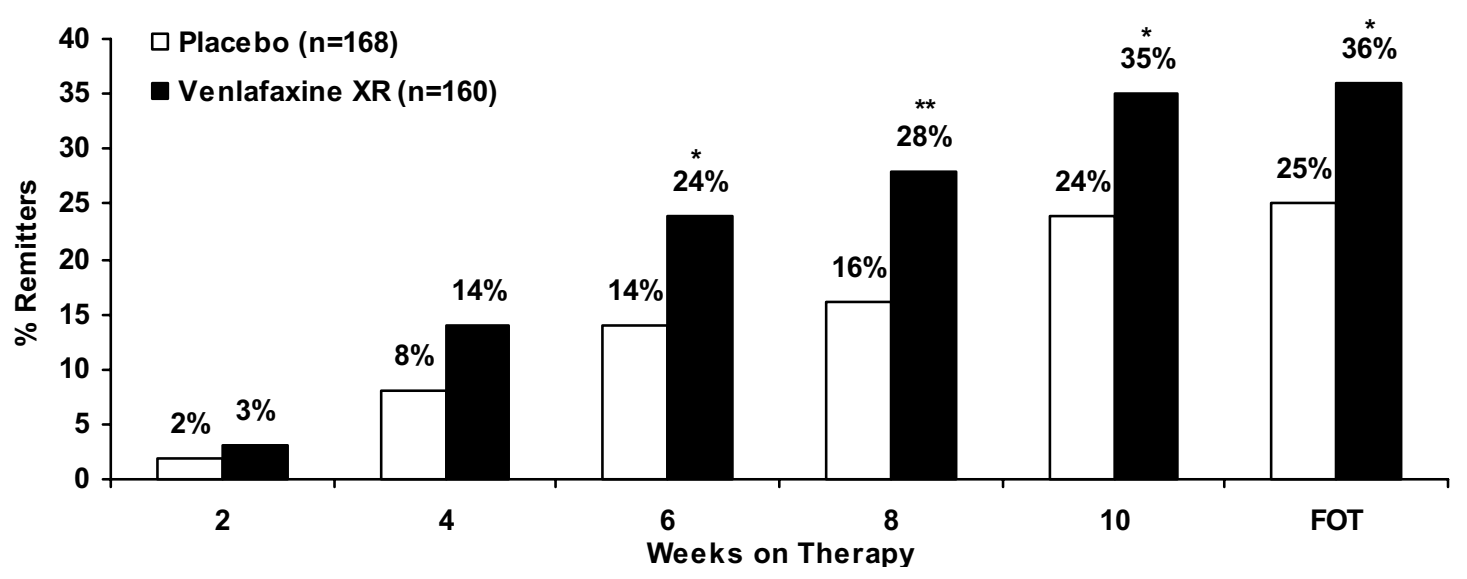

Figure 2 Remission rates with venlafaxine XR and placebo over time. Copyright @ 2005. Reprinted with permission from Bradwejn J, Ahokas A, Stein DJ, et al. 2005. Venlafaxine extended-release capsules in panic disorder: Flexible-dose, double-blind, placebo-controlled study. Br J Psychiatry, I87:352-9.

Note: ${ }^{*} \mathrm{p}<0.05$ vs placebo, ** ${ }^{*}<0.01$ vs placebo; Remission defined as panic-free (PASS) and CGI-I=I; ITT, population; LOCF, last observation carried forward; FOT, final on-therapy evaluation.

Abbreviations: CGI-I, Clinical Global Impressions - Improvement; ITT, intent-to-treat; XR, extended release. 
general, school/course work and household duties subscales were more resistant to improvement with treatment. Both the $75 \mathrm{mg}$ and $225 \mathrm{mg}$ doses of venlafaxine XR, as well as paroxetine, were superior to placebo on all 4 SDS subscales $(\mathrm{p}<0.01)($ Khandker et al 2005).

\section{Predictors of response to venlafaxine}

A pooled analysis of the four major clinical trials, including a total of 1595 adults with panic disorder, evaluated predictors of clinical outcomes in the short-term treatment of panic disorder (Pollack et al 2006). Greater mean symptom severity and female gender were associated with lower proportions of panic-free patients, in both the venlafaxine XR and the placebo treated group. Among patients treated with venlafaxine XR, $69 \%$ of those classified as low severity at baseline were panic free at endpoint compared with $51 \%$ of patients in the high severity group $(p<0.05)$. Similarly, $65 \%$ of men achieved panic-free status compared with $57 \%$ of women $(p<0.05)$. For those treated with placebo, significantly more patients in the low severity group (53\%), compared with the high severity group (32\%), and men (50\%) compared with women (40\%), were panicfree at endpoint.

\section{Safety and tolerability of venlafaxine $X R$ in panic disorder}

In general, the incidence and severity of treatment-emergent adverse events observed with venlafaxine XR in panic disorder were similar to those observed in studies for depression, generalized anxiety disorder, and social anxiety disorder (Pollack and Whitaker 2003; Liebowitz et al 2004; Bradwejn et al 2005; Ferguson et al 2005; Pollack et al 2005; Albano et al 2006).

In placebo-controlled trials, the most common treatmentemergent adverse events reported by at least $5 \%$ of patients in the venlafaxine XR group, and at least twice the rate of placebo, were: insomnia, dry mouth, sweating, abnormal ejaculation/orgasm, constipation, decreased libido, somnolence, anorexia, palpitations, vasodilatation, hypertension, nausea, accidental injury, and impotence (Liebowitz et al 2004; Bradwejn et al 2005; Ferguson et al 2005). In these trials, treatment discontinuation due to adverse events were reported in $1 \%-9 \%$ of venlafaxinetreated patients compared with $2 \%-4 \%$ in the placebo group (Liebowitz et al 2004; Bradwejn et al 2005; Ferguson et al 2005).

In comparative trials with paroxetine, adverse events were similar in both active treatment groups (Pollack and
Whitaker 2003; Pollack et al 2005). Discontinuations due to adverse events were similar between the groups in comparative trials: $2 \%-8 \%$ in the venlafaxine XR $75 \mathrm{mg}$ group, $12 \%$ in the venlafaxine XR $150 \mathrm{mg}$ group, $<1 \%$ in the venlafaxine XR $225 \mathrm{mg}$ group, $5 \%-10 \%$ in the paroxetine $40 \mathrm{mg}$ group, and $2 \%-9 \%$ in the placebo group (Pollack and Whitaker 2003; Pollack et al 2005).

In the long-term trial, venlafaxine XR-treated patients were significantly less likely to withdraw from the study for any reason compared with patients treated with placebo $(\mathrm{p}<0.001)$ (Ferguson et al 2005).

\section{Potential drug interactions}

Venlafaxine is metabolized by the cytochrome P450 isoenzyme 2D6 and therefore its metabolism is modified by medications that inhibit or induce this enzyme. Venlafaxine is also an inhibitor of 2D6 so it modifies the elimination of compounds metabolized by this enzyme. Although potentially clinically significant, the degree of 2D6 inhibition with venlafaxine is less than that seen with certain SSRIs, such as paroxetine, fluoxetine, fluvoxamine, and sertraline (Otton et al 1996). Minor interactions have been reported between venlafaxine and lithium, diazepam, haloperidol, and bupropion (Troy et al 1996; Benazzi 1997; Mekler and Woggon 1997; Kudo and Ishizaki 1999; Kennedy et al 2002). Cimetidine should be co-administered with caution in patients with compromised hepatic metabolic function (Troy et al 1998). Venlafaxine should be used cautiously in patients receiving indinavir to avoid significant decreases in indinavir serum levels (Levin et al 2001). As is the case with most antidepressant drugs, a potential interaction with monoamine oxidase inhibitors (MAOIs) exists and serious adverse reactions have been reported (Brubacher et al 1996; Gitlin 1997; Hodgman et al 1997).The combination of a SSRI, clomipramine or venlafaxine XR and a MAOI poses a significant risk for life-threatening serotonin syndrome.

\section{Antidepressant discontinuation syndrome}

As with TCAs, MAOIs, and SSRIs, discontinuation symptoms have been reported with venlafaxine XR (Pinzani et al 2000; Haddad 2001; Haddad et al 2001; Reeves et al 2003; Nissen et al 2005). In addition to the common discontinuation symptoms including dizziness, electric shock-like sensations, anxiety, agitation, dysphoria, weeping for no reason, and flu-like symptoms, other rare symptoms have been described, including narcolepsy-cataplexy 
syndrome, and neurologic symptoms mimicking stroke. Onset of discontinuation symptoms can be associated with stopping the antidepressant, reducing the dosage or taking the venlafaxine XR later in the day than usual. Clinicians should be aware of these discontinuation syndromes, since misdiagnosis may result in inappropriate diagnostic tests and treatment, as well as unnecessary patient morbidity (Haddad et al 2001). Most reactions are mild. More severe cases should be treated symptomatically or the antidepressant can be reinstated. Discontinuation symptoms have not been well studied and most recommendations are based on anecdotal data or expert opinion (Haddad 2001; Schatzberg et al 2006). However, strategies include gradual discontinuation of antidepressant therapy, clinical monitoring, and patient education (Schatzberg et al 2006). Anecdotally, the author has found the central $\alpha-2$ agonist, clonidine, in low doses ( $0.05 \mathrm{mg}$ twice daily), helpful for some of the more disturbing symptoms (dizziness, electric shock-like sensations) suggesting a possible noradrenergic rebound mechanism contributing to the constellation of discontinuation symptoms.

\section{Summary and clinical perspective}

Venlafaxine XR is effective and well tolerated in both the short- and long-term treatment of panic disorder. Achieving a panic-free state is a challenging treatment goal, but venlafaxine XR has been shown to produce significantly higher response and remission rates than placebo, and was as effective as paroxetine in comparative trials. In the one comparative trial, the venlafaxine XR $225 \mathrm{mg}$ group had a significantly higher percentage of panic-free patients and a greater PDSS score improvement at endpoint than paroxetine (Pollack et al 2005). Importantly, venlafaxine XR significantly improved patient quality of life and functioning, and was generally well tolerated. Encouraging patients to face their fears in exposure-based CBT is also an important aspect of treatment.

Since patients with panic disorder are often sensitive to side effects (agitation, jitteriness, increased anxiety, and panic attacks) early in the treatment with antidepressants, the starting dose of venlafaxine XR should be low $(37.5 \mathrm{mg}$ per day) for at least the first week. Once tolerated at $37.5 \mathrm{mg}$ per day, the dose may then be increased to $75 \mathrm{mg}$ per day for 2 weeks before increasing again to $150 \mathrm{mg}$. If there is no appreciable benefit at $150 \mathrm{mg}$ after 4-6 weeks, the dose may then be increased to $225 \mathrm{mg}$ per day for $4-6$ weeks before considering further increases to doses as high as
$375 \mathrm{mg}$ per day, if required. Clinical trials did not evaluate doses beyond $225 \mathrm{mg}$ per day, so doses above $225 \mathrm{mg}$, while often required in clinical practice to treat "real world" patients with co-morbid depression and other anxiety disorders, are considered off-label. Although fixed-dose clinical trials did not show a statistically significant treatment effect difference between $75 \mathrm{mg}$ and $225 \mathrm{mg}$ per day, there was a numerical trend suggesting possible superiority of higher doses, which is often seen in clinical practice.

Three flexible dose trials (Liebowitz et al 2004; Bradwejn et al 2005; Ferguson et al 2005) had mean daily doses between 115-194.1 mg per day. Depending on the outcome measure, therapeutic benefits including response and sustained remission, in clinical trials, usually separated from placebo at 4-6 weeks. There was further accrual of therapeutic benefit in a greater number of study subjects when treating beyond 6 weeks (eg, in the Pollack et al 2005 trial, the percentage of remitters increased from approximately $18 \%$ at 6 weeks to approximately $50 \%$ at 12 weeks). This underscores the need in clinical practice to be patient while awaiting the onset of therapeutic effect in panic patients. When compared with treating major depression without comorbidity, one should start at lower doses of antidepressants (eg, $37.5 \mathrm{mg}$ venlafaxine XR), generally proceed to higher minimum target doses (eg, 150-225 mg venlafaxine $\mathrm{XR}$ ) and wait longer for onset of therapeutic benefit (sometimes 8-12 weeks) when treating panic disorder.

There is little empirical evidence to guide clinicians regarding the length of treatment with antidepressants for panic disorder. General consensus among experts in the treatment of anxiety disorders is that anxiety disorder treatment should be longer than that recommended for an index episode of depression. The author usually treats for 2 years after panic attacks have ceased, at the dose required to stop the panic attacks. Adequate time is necessary for exposure through behavioral therapy to minimize or eradicate agoraphobic avoidance. The antidepressant would then be tapered slowly over a period of 6 months while observing for any signs of recurrence.

\section{References}

Albano A, Tourian K, Tzanis E, et al. 2006. Venlafaxine ER in adolescents with panic disorder [Abstract]. Paper presented at: Anxiety Disorders Association of America (ADAA); March 23-26, Miami, Florida. 355.

Albert CM, Chae CU, Rexrode KM, et al. 2005. Phobic anxiety and risk of coronary heart disease and sudden cardiac death among women. Circulation, 111:480-7. 
Allgulander C, Mangano R, Zhang J, et al. 2004. Efficacy of venlafaxine ER in patients with social anxiety disorder: a double-blind, placebocontrolled, parallel-group comparison with paroxetine. Hum Psychopharmacol, 19:387-96.

[APA] American Psychiatric Association. 2000. Diagnostic and statistical manual of mental disorders, text revised (DSM-IV-TR), 4th ed. Washington, DC: APA.

Angst J. 1996. Comorbidity of mood disorders: a longitudinal prospective study. Br J Psychiatry Suppl, 31-7.

Bakker A, van Balkom A, Spinhoven P. 2002. SSRIs vs TCAs in the treatment of panic disorder: a meta-analysis. Acta Psychiatr Scand, 106:163-7.

Ballenger J. 2001. Treatment of anxiety disorders to remission. J Clin Psychiatry, 62(Suppl 12):5-9.

Bandelow B, Zohar J, Hollander E, et al. 2002. World Federation of Societies of Biological Psychiatry (WFSBP) guidelines for the pharmacological treatment of anxiety, obsessive-compulsive and posttraumatic stress disorders. World J Biol Psychiatry, 3:171-99.

Benazzi F. 1997. Urinary retention with venlafaxine-haloperidol combination. Pharmacopsychiatry, 30:27.

Blier P, Szabo S. 2005. Potential mechanisms of action of atypical antipsychotic medications in treatment-resistant depression and anxiety. J Clin Psychiatry, 66(Suppl 8):30-40.

Bradwejn J, Ahokas A, Stein DJ, et al. 2005. Venlafaxine extended-release capsules in panic disorder: Flexible-dose, double-blind, placebocontrolled study. Br J Psychiatry, 187:352-9.

Brubacher J, Hoffman R, Lurin M. 1996. Serotonin syndrome from venlafaxine-tranylcypromine interaction. Vet Hum Toxicol, 38:358-61.

Canadian Journal of Psychiatry Clinical Practice Guidelines. 2006. Management of anxiety disorders. Can J Psychiatry, 51(Suppl 2):9-91S

Cecchi M, Khoshbouei H, Javors M, et al. 2002. Modulatory effects of norepinephrine in the lateral bed nucleus of the stria terminalis on behavioral and neuroendocrine responses to acute stress. Neuroscience, 112:13-21.

Coryell W, Endicott J, Andreasen NC, et al. 1988. Depression and panic attacks: the significance of overlap as reflected in follow-up and family study data. Am J Psychiatry, 145:293-300.

Eaton WW, Kessler RC, Wittchen HU, et al. 1994. Panic and panic disorder in the United States. Am J Psychiatry, 151:413-20.

Fawcett J. 1997. The detection and consequences of anxiety in clinical depression. J Clin Psychiatry, 58(Suppl 8):35-40.

Ferguson J, Whitaker T, Mangano R, et al. 2005; Preventing relapse of panic disorder in adult outpatient responders to venlafaxine XR. Presented at Anxiety Disorders Association of America (ADAA); March 17-21, Seattle, Washington.

Frank E, Prien R, Jarrett R, et al. 1991. Conceptualization and rationale for consensus definitions of terms in major depressive disorder. Remission, recovery, relapse, and recurrence. Arch Gen Psychiatry, 48:851-5.

Gelenberg A, Lydiard R, Rudolph R, et al. 2000. Efficacy of venlafaxine extended-release capsules in nondepressed outpatients with generalized anxiety disorder: A 6-month randomized controlled trial. JAMA, 283:3082-8.

Gitlin M. 1997. Venlafaxine, monoamine oxidase inhibitors, and the serotonin syndrome. J Clin Psychopharmacol, 17:66-7.

Goodwin R, Olfson M, Feder A, et al. 2001. Panic and suicidal ideation in primary care. Depress Anxiety, 14:244-6.

Goodwin RD, Jacobi F, Thefeld W. 2003. Mental disorders and asthma in the community. Arch Gen Psychiatry, 60:1125-30.

Haddad PM. 2001. Antidepressant discontinuation syndromes. Drug Saf, 24:183-97.

Haddad PM, Devarajan S, Dursun SM. 2001. Antidepressant discontinuation (withdrawal) symptoms presenting as 'stroke'. $J$ Psychopharmacol, 15:139-41.

Hodgman M, Martin T, Krenzelok E. 1997. Serotonin syndrome due to venlafaxine and maintenance tranylcypromine therapy. Hum Exp Toxicol, 16:14-17.
Katerndahl DA, Realini JP. 1997. Quality of life and panic-related work disability in subjects with infrequent panic and panic disorder. $J$ Clin Psychiatry, 58:153-8.

Kawachi I, Colditz GA, Ascherio A, et al. 1994. Prospective study of phobic anxiety and risk of coronary heart disease in men. Circulation, 89:1992-7.

Kawachi I, Sparrow D, Vokonas PS, et al. 1994. Symptoms of anxiety and risk of coronary heart disease. The Normative Aging Study. Circulation, 90:2225-9.

Kennedy SH, McCann SM, Masellis M, et al. 2002. Combining bupropion SR with venlafaxine, paroxetine, or fluoxetine: a preliminary report on pharmacokinetic, therapeutic, and sexual dysfunction effects. $J$ Clin Psychiatry, 63:181-6.

Kessler RC, Berglund P, Demler O, et al. 2005. Lifetime prevalence and age-of-onset distributions of DSM-IV disorders in the National Comorbidity Survey Replication. Arch Gen Psychiatry, 62:593-602.

Kessler RC, Chiu WT, Demler O, et al. 2005. Prevalence, severity, and comorbidity of 12-month DSM-IV disorders in the National Comorbidity Survey Replication. Arch Gen Psychiatry, 62:617-27.

Khandker R, Zhang H, Gao B. 2005; Patient-reported quality of life and functionality in panic disorder: venlafaxine, paroxetine, and placebo. Paper presented at: Anxiety Disorders Association of America; March 17-21, Seattle, Washington

Kudo S, Ishizaki T. 1999. Pharmacokinetics of haloperidol: an update. Clin Pharmacokinet, 37:435-56.

Levin G, Nelson L, De Vane C, et al. 2001. A pharmacokinetic drug-drug interaction study of venlafaxine and indinavir. Psychopharmacol Bull, 35:62-71.

Liebowitz M, Asnis G, Tzanis E, et al. 2004. Venlafaxine extended release versus placebo in the short-term treatment of panic disorders [abstract]. In: American Psychiatric Association (ed). New Research Abstracts, Annual Meeting of the American Psychiatric Association, May 1-6, Washington, DC., 194.

MacKinnon DF, Zandi PP, Cooper J, et al. 2002. Comorbid bipolar disorder and panic disorder in families with a high prevalence of bipolar disorder. Am J Psychiatry, 159:30-5.

McIntosh A, Cohen A, Turnbull N, et al. 2004. Clinical guidelines and evidence review for panic disorder and generalised anxiety disorder. Sheffield: University of Sheffield/London: National Collaborating Centre for Primary Care.

Mekler G, Woggon B. 1997. A case of serotonin syndrome caused by venlafaxine and lithium. Pharmacopsychiatry, 30:272-3.

Ministry of Health. 2003. Clinical practice guidelines: anxiety disorders. Singapore: Ministry of Health, pp 1-75.

Morilak DA, Frazer A. 2004. Antidepressants and brain monoaminergic systems: a dimensional approach to understanding their behavioural effects in depression and anxiety disorders. Int $J$ Neuropsychopharmacol, 7:193-218.

Muth E, Haskins J, Moyer J, et al. 1986. Antidepressant biochemical profile of the novel bicyclic compound Wy-45,030, an ethyl cyclohexanol derivative. Biochem Pharmacol, 35:4493-7.

Nagy LM, Krystal JH, Charney DS, et al. 1993. Long-term outcome of panic disorder after short-term imipramine and behavioral group treatment: 2.9-year naturalistic follow-up study. $J$ Clin Psychopharmacol, 13:16-24

Nagy LM, Krystal JH, Woods SW, et al. 1989. Clinical and medication outcome after short-term alprazolam and behavioral group treatment in panic disorder. 2.5 year naturalistic follow-up study. Arch Gen Psychiatry, 46:993-9.

Nissen C, Feige B, Nofzinger E, et al. 2005. Transient narcolepsy-cataplexy syndrome after discontinuation of the antidepressant venlafaxine. $J$ Sleep Res, 14:207-8.

Norton GR, Harrison B, Hauch J, et al. 1985. Characteristics of people with infrequent panic attacks. $J$ Abnorm Psychol, 94:216-21.

Noyes R, Jr., Garvey MJ, Cook BL. 1989. Follow-up study of patients with panic disorder and agoraphobia with panic attacks treated with tricyclic antidepressants. J Affect Disord, 16:249-57. 
Otto MW, Tuby KS, Gould RA, et al. 2001. An effect-size analysis of the relative efficacy and tolerability of serotonin selective reuptake inhibitors for panic disorder. Am J Psychiatry, 158:1989-92.

Otton SV, Ball SE, Cheung SW, et al. 1996. Venlafaxine oxidation in vitro is catalysed by CYP2D6. Br J Clin Pharmacol, 41:149-56.

Pardon MC, Gould GG, Garcia A, et al. 2002. Stress reactivity of the brain noradrenergic system in three rat strains differing in their neuroendocrine and behavioral responses to stress: implications for susceptibility to stress-related neuropsychiatric disorders. Neuroscience, 115:229-42.

Paykel ES. 1998. Remission and residual symptomatology in major depression. Psychopathology, 31:5-14.

Pinzani V, Ginies E, Robert L, et al. 2000. Venlafaxine withdrawal syndrome: report of six cases and review of the literature. Rev Med Interne, 21:282-4.

Pollack M, Emilien G, Tzanis E, et al. 2004; Short-term treatment of panic disorder with venlafaxine XR and paroxetine. Presented at: World Congress of Women's Mental Health; March 17-20, Washington, DC

Pollack M, Stein DJ, Mangano R, et al. 2006; Venlafaxine XR in the shortterm treatment of panic disorder: A pooled analysis of predictors [Abstract]. Presented at: Anxiety Disorders Association of America (ADAA); March 23-26, Miami, Florida

Pollack M, Whitaker T. 2003; Randomized, placebo-controlled trial of venlafaxine XR and paroxetine in the short-term treatment of panic disorder [poster]. Presented at: Anxiety Disorders Association of America (ADAA); March 27-30, Toronto, Canada

Pollack M, Whitaker T, Mangano R, et al. 2005; Short-term treatment of panic disorder: a comparison of venlafaxine XR vs paroxetine or placebo. Presented at: Anxiety Disorders Association of America (ADAA); March 17-21, Seattle, Washington.

Pollack MH, Worthington JJ, 3rd, Otto MW, et al. 1996. Venlafaxine for panic disorder: results from a double-blind, placebo-controlled study. Psychopharmacol Bull, 32:667-70.

Ramage-Morin PL. 2004. Panic disorder and coping. Health Rep, 15(Suppl):31-43.

Reeves RR, Mack JE, Beddingfield JJ. 2003. Shock-like sensations during venlafaxine withdrawal. Pharmacotherapy, 23:678-81.

Royal Australian and New Zealand College of Psychiatrists. 2003. Australian and New Zealand Clinical practice guidelines for the treatment of panic disorder and agoraphobia. Aust N Z J Psychiatry, 37:641-56.

Roy-Byrne P, Wingerson D, Cowley D, et al. 1993. Psychopharmacologic treatment of panic, generalized anxiety disorder, and social phobia. Psychiatr Clin North Am, 16:719-35.

Roy-Byrne PP, Stang P, Wittchen HU, et al. 2000. Lifetime panicdepression comorbidity in the National Comorbidity Survey. Association with symptoms, impairment, course and help-seeking. Br J Psychiatry, 176:229-35.
Schatzberg AF, Blier P, Delgado PL, et al. 2006. Antidepressant discontinuation syndrome: consensus panel recommendations for clinical management and additional research. J Clin Psychiatry, 67:2730 .

Shear MK, Maser JD. 1994. Standardized assessment for panic disorder research. A conference report. Arch Gen Psychiatry, 51:346-54.

Sherbourne CD, Wells KB, Judd LL. 1996. Functioning and well-being of patients with panic disorder. Am J Psychiatry, 153:213-8.

Simon NM, Blacker D, Korbly NB, et al. 2002. Hypothyroidism and hyperthyroidism in anxiety disorders revisited: new data and literature review. J Affect Disord, 69:209-17.

Smith D, Dempster C, Glanville J, et al. 2002. Efficacy and tolerability of venlafaxine compared with selective serotonin reuptake inhibitors and other antidepressants: a meta-analysis. $B r J$ Psychiatry, 180:396-404.

Staab JP, Ruckenstein MJ, Solomon D, et al. 2002. Exertional dizziness and autonomic dysregulation. Laryngoscope, 112:1346-50.

Sullivan GM, Kent JM, Kleber M, et al. 2004. Effects of hyperventilation on heart rate and QT variability in panic disorder pre- and posttreatment. Psychiatry Res, 125:29-39.

Troy S, Parker V, Hicks D, et al. 1996. Pharmacokinetic interaction between multiple-dose venlafaxine and single-dose lithium. J Clin Pharmacol, $36: 175-81$.

Troy S, Rudolph R, Mayersohn M, et al. 1998. The influence of cimetidine on the disposition kinetics of the antidepressant venlafaxine. $J$ Clin Pharmacol, 38:467-74.

Tucker P, Adamson P, Miranda R, Jr., et al. 1997. Paroxetine increases heart rate variability in panic disorder. $J$ Clin Psychopharmacol, 17:370-6.

Weissman M, Bland R, Canino G, et al. 1997. The cross-national epidemiology of panic disorder. Arch Gen Psychiatry, 54:305-9.

Weissman MM, Wolk S, Wickramaratne P, et al. 1999. Children with prepubertal-onset major depressive disorder and anxiety grown up. Arch Gen Psychiatry, 56:794-801.

Wulsin LR, Hillard JR, Geier P, et al. 1988. Screening emergency room patients with atypical chest pain for depression and panic disorder. Int J Psychiatry Med, 18:315-23.

Yeragani VK, Pohl R, Jampala VC, et al. 2000. Increased QT variability in patients with panic disorder and depression. Psychiatry Res, 93:22535 .

Zandbergen J, Bright M, Pols H, et al. 1991. Higher lifetime prevalence of respiratory diseases in panic disorder? Am J Psychiatry, 148:15835.

Zhang H, Mallick R, Gao B. 2004. Patient perceptions of quality of life and functionality in panic disorder: A comparison of venlafaxine XR, paroxetine and placebo. Presented at: International Congress of Biological Psychiatry; February 9-13, Sydney, Australia 
